\title{
An Investigation on The Effect Of Calcite Bacteria Seeding On Shear Strength Of Peat Soil Via An Unconfined Compression Test
}

\author{
Sidek, N. ${ }^{3}{ }^{*}$, Abdul-Talib, S. ${ }^{1}$, Mohd Zain, N. ${ }^{2}$, Rashid, N.R.N.A . ${ }^{2}$ \\ and Abu Bakar, I.A. ${ }^{2}$ \\ ${ }^{1}$ Professor, Faculty of Civil Engineering, UiTM Malaysia \\ ${ }^{2}$ Lecturer, Faculty of Civil Engineering, UiTM Malaysia \\ ${ }^{3}$ Post Graduate Student Faculty of Civil Engineering, UiTM Malaysia, \\ norbayasidek@gmail.com
}

\begin{abstract}
Keywords: Microbiological work, Peat soils, Physical and Engineering Properties, Soil treatment, Unconfined Compression Test
\end{abstract}

\begin{abstract}
Peat soils have been known for their problematic characteristics which include high water content, high compressibility and low shear strength. In this study, an attempt was made to investigate the effect of 1 week addition of modified Urea-CaCl2 liquid medium with and without Sporosarcina pasteurii on the shear strength of unsterilized dried peat soil using the Unconfined Compression Test. After the treatment period, significant increase in the shear strength of the soil was found to be highest for peat + medium at $42 \mathrm{kN} / \mathrm{m} 2$, moderate for peat + medium + Sporosarcina pasteurii at $27 \mathrm{kN} / \mathrm{m} 2$ and unchanged for peat + water control at $24 \mathrm{kN} / \mathrm{m} 2$. Although the growth dynamics of all the microbes involved in the calcite formation in the treated peat soil were not known, the addition of the modified Urea-CaCl2 liquid medium into the soil clearly had contributed to the marked increased in the shear strength of the soil. It is probable that the medium had promoted a better growth of indigenous calcite bacteria population in the soil which may have been suppressed by the slow growing S. pasteurii population being added daily to the soil.
\end{abstract}

\section{Introduction}

Peat soil which consists of partly decomposed biomass are normally found in wet coastal regions of West Malaysia. The periodically high water table of the peat soil areas often prevent the aerobic decomposition of plant debris causing the rate of biomass accumulation of decaying plant materials to become greater than that of the rate of decomposition of these materials. In light of this, the peat soil has become one of the most problematic soil that require appropriate pretreatment to improve the soil engineering properties especially the soil strength. The effectiveness of calcite forming bacteria in efforts to improve soil, sand and concrete structures has been reported by many researchers including Hammes et al. (2003), DeJong et al.(2006), Sarda et al. (2009), Ramakrishnan et al. (2005). Crawford et.al (2010) have registered in the U.S, a patented technique of in situ precipitation of $\mathrm{CaCO}_{3}$ by microorganisms to improve the mechanical properties of a geomaterial. In this technique, many naturally occurring soil bacteria of the genera Bacillus, Sporosarcina, Sporolactobacillus, Clostridium and Desulfotomaculum were reported to be able to hydrolyze urea in presence of water to ammonium and carbonate ions by the following reaction,

$$
\left(\mathrm{NH}_{2}\right)_{2} \mathrm{CO}+2 \mathrm{H}_{2} \mathrm{O} \rightarrow 2 \mathrm{NH}_{4}^{+}+\mathrm{CO}_{3}{ }^{2-}
$$

The generation of the $\mathrm{NH}_{4}{ }^{+}$ions increases the local $\mathrm{pH}$ and in the presence of calcium ions react spontaneously with the calcium ions to form calcium carbonate by the following reaction,

$$
\mathrm{Ca}^{2+}+\mathrm{CO}_{3}^{2-} \rightarrow \mathrm{CaCO}_{3}
$$

Calcium carbonate will spontaneously form stable polymorph calcite crystals which cement soil grains together, hence the biocementation process has been conceived to be useful in many 
application. The soil improvement techniques via biocalcification process need to be designed and proven over time to ensure that the techniques are easily applicable, convenient, cost effective and having a lasting impact on improving the soil engineering property. The future prospect of using microbes to improve the strength of peat soil would require a much more practical and sustainable approach such as by the use of wastewater with appropriate urea composition as a substitute for the commercial media used in the laboratory. Considering the multidimensional interaction of parameters that will influence the effectiveness of the biocalcification process in the natural environment, success in laboratory experiments may not be equally so in field trials.

\section{Scope of Study}

The treatment and recovery of the problematic peat soil via strain-specific biocalcification or ureolytic microbial carbonate precipitation would be attempted in this study. The seeding of $S$. pasteurii in peat soil would be expected to produce an alkaline condition and nucleation sites in the soil which were known to cause formation of calcite crystals between the soil particles. The investigated parameter of this study would be focused on the shear strength behavior of the unsterilized dried peat soil before and after seeding of the soil with a liquid media containing a fixed concentration of the $S$. pasteurii for a treatment period of 1 week at an ambient temperature of $37^{\circ} \mathrm{C}$.

\section{Materials and Methods}

Preparation of the Modified Urea-CaCl 2 medium containing Sporosarcina pasteuri. Sporosarcina pasteurii is one of several common calcite forming bacteria that inhabit the soil and rock of limestone caves. A stock culture of this species in a Urea-CaCl${ }_{2}$ agar medium (Sung-Jin et. al., 2009) was obtained from the Biomolecular Science Department of the Faculty of Applied Science, UiTM, Shah Alam . A loop full of this bacteria from a stock culture was inoculated into a $100 \mathrm{ml}$ of modified Urea-CaCl 2 liquid medium containing $\mathrm{CaCl}_{2} \quad 0.4 \mathrm{~g}$; urea $2 \mathrm{~g}$ and nutrient broth powder $1.6 \mathrm{~g}$, which were dissolved in $100 \mathrm{ml}$ of water and the $\mathrm{pH}$ adjusted to 8.5 . The flask containing the culture was then placed on an orbital shaker at $130 \mathrm{rpm}$ and incubated at $37^{\circ} \mathrm{C}$ for a period of 3 weeks. The bacterial suspension in the flask was adjusted to $0.8 \mathrm{OD}_{600}$ by the addition of cell biomass from other 3 weeks old culture centrifuged at $8000 \mathrm{rpm}$. The three types of soil treatment medium prepared for use in this study were plain water (W), Urea- $\mathrm{CaCl}_{2}$ medium without $S$. pasteurii $(\mathrm{No})$ and Urea-CaCl 2 medium with $S$. pasteurii $\left(\mathrm{N}_{\mathrm{sp}}\right)$.

Microscopic Observation of Calcite Crystals. A bacterial colony growing on Urea-CaCl $\mathrm{C}_{2}$ agar plate was cut and scooped out as a square piece of agar using the cover slip and carefully placed on to a glass slide without trapping air bubbles. A drop of methylene blue stain was dropped on the bacterial colony before a cover slip was placed over it. Observation for presence of calcite crystals around bacterial cells in the agar was made under high dry and oil immersion objectives of a phase contrast light microscope.

Treatment of Peat Soil with Bacteria. Peat soil in this study was obtained from a palm oil estate in Kapar, Selangor. The soil was dried, crushed and sieved through $2 \mathrm{~mm}$ pore size sieve. Three separate trays of unsterilized oven-dried peat soils were prepared with each tray containing $0.7 \mathrm{~kg}$ of peat soil spread out at about 1 inch in height throughout the tray to ensure sufficient aeration of the soil (see Figure 1). 


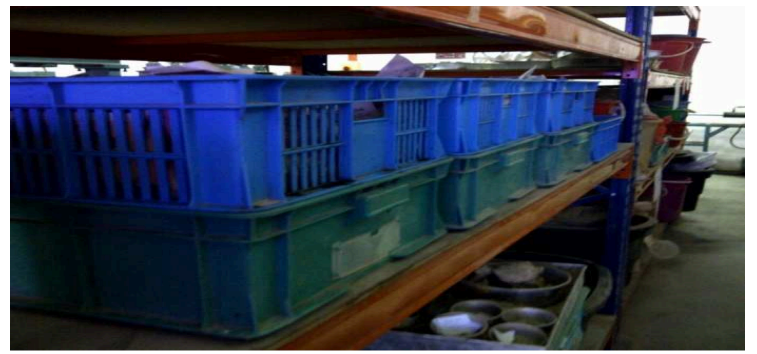

Fig. 1: The preparation of peat soils with different types of liquids mixtures.

The soil in the first tray was homogenously mixed with $400 \mathrm{ml}$ of water (W), the soil in the second tray was mixed with $400 \mathrm{ml}$ of Urea-CaCl${ }_{2}$ medium without $S$. pasteurii (No) and the soil in the third tray was mixed with $400 \mathrm{ml}$ of Urea-CaCl 2 medium with $S$. pasteurii $\left(\mathrm{N}_{\mathrm{sp}}\right)$. All the soil in the trays were turn over every 12 hours to allow for sufficient aeration of the soil to occur. The trays were then covered with newspaper and kept at ambient temperature of $37^{\circ} \mathrm{C}$. The same treatment was repeated to the same soil sample daily for a period of 7 days.

Soil Testing Procedure. After the 1 week treatment period, all the soil samples were dried so as to contain the same level of moisture content. The shear strength of the soil samples treated and untreated with Sporosarcina pasteurii were then tested using the Unconfined Compression Test (UCT) machine. The tested soil samples were handled under controlled condition during the testing period to ensure that any imperfections due to the surrounding factors were mostly eliminated. As for the UCT procedure, the soil sample was molded into the compaction mould measuring $50 \times 100$ $\mathrm{mm}$ in dimension. The UCT procedure was carried out on the control soil sample W, followed by soil sample $\mathrm{N}_{\mathrm{o}}$ and finally with soil sample $\mathrm{N}_{\mathrm{SP}}$.

\section{Experimental Results and Discussions}

Formation of calcite crystals in the vicinity of bacterial colonies on Urea-CaCl2 agar medium. According to Castanier et al. (1999), the process of $\mathrm{pH}$ increment is started with the process of hydrolysis of the urea while the utilization of organics acids could also lead to the increase of $\mathrm{pH}$ level and the concentration of the dissolve inorganic carbon. Hammes et al. (2003) reported that the negatively charged surface of microbial cell wall favor the binding of divalent $\mathrm{Ca}^{2+}$ cations thereby making microorganisms ideal crystal nucleation sites. Generally, the formation of calcite crystals around the slow growing bacterial colonies were visible to the naked eye as small dark particulate spots on the agar surface of the 1-5 days old plate culture. Upon observing the colonies of $S$. pasteurii from the agar media culture under the dry objective and oil immersion objectives, various sizes of calcite crystals were observed as shown in Figure 2.

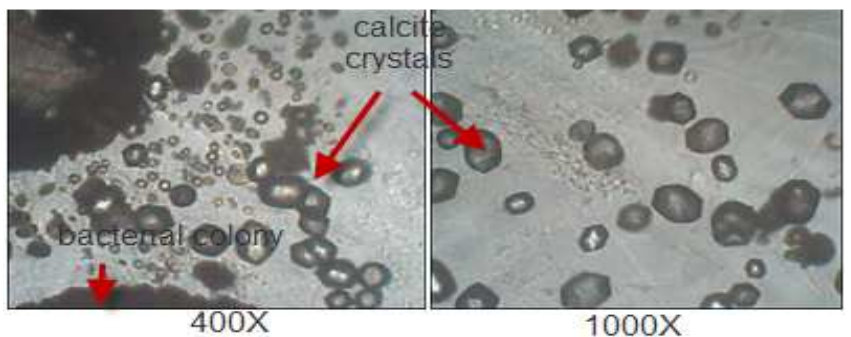

Fig. 2: Calcite crystals around bacterial colony at $400 \mathrm{X}$ and 1000X magnification

\section{Comparison of Shear Strength of Peat Soils Treated and Untreated with Calcite Bacteria.} Shear strength is defined as the rate of load increment applied to the soil until the soil reached its limit and deformed excessively. The yielding point is determined by the maximum stress the soil could resist prior to time of failure. The common failure could be obtained through the Mohr 
Coulomb criterion. Theoretically, the failures of the strain were developed based on the stress-strain relationship of the soils. Here, the linear stress-strain assumptions were made since the soil samples were homogenous and isotropic in behaviors. In contrary, there would be non-linear stress-strain relationships if the soils were to be non-homogeneous and exhibit anisotropy. The soil sample preparations and testing procedures followed were according to the procedures of BS 1377 and ASTM D 2974.

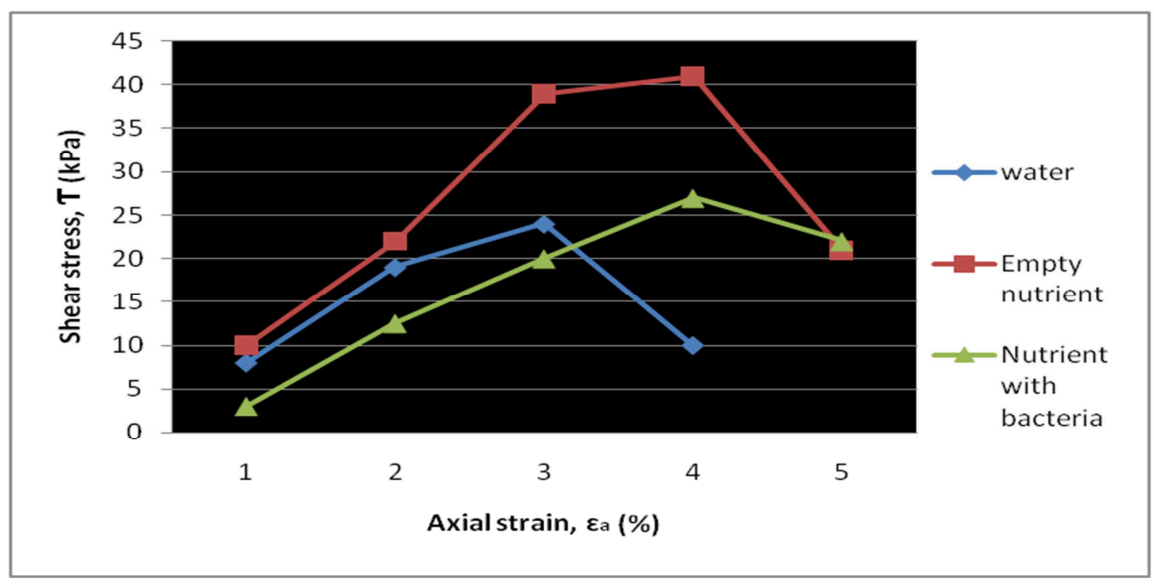

Fig. 3: Comparison of shear strength of three peat soil samples before treatment and after treatment with $S$. pasteurii.

As shown in Figure 3, the highest shear strength was obtained for soil $1_{\text {No }}$ mixed with media without $S$. pasteurii $\left(42 \mathrm{kN} / \mathrm{m}^{2}\right)$, followed by soil ${ }_{\mathrm{Nsp}}$ mixed with media containing $S$. pasteurii $\left(27 \mathrm{kN} / \mathrm{m}^{2}\right)$ and finally soil $\mathrm{w}_{\mathrm{w}}$ mixed with water as control $\left(24 \mathrm{kN} / \mathrm{m}^{2}\right)$. It is interesting to note that the shear strength of the peat soil mixed with media without $S$. pasteurii is almost twice that of the soil mixed with media without that bacterial species. Besides the increased in the shear strengths of the soil treated with the modified Urea-CaCl 2 medium (with or without $S$. pasteurii), it can also be seen that a decrement in shear stress had occurred after the maximum shear stress has been attained.

\section{Conclusions}

Microbiological and soil engineering works had been utilized in defining the soil treatment phases. It was observed that the usage of the calcite producing microbes were able to increase the shear strength of the peat soils. However, the modified Urea-CaCl $\mathrm{Cl}_{2}$ medium without S. pasteurii had showed the highest shear strength among all. The influence of other indigenous soil bacteria present in the dried unsterilized peat as well as other organic contents of the soil could have been the caused of this observed phenomenon. The soil sample with full concentration of $S$. pasteurii had showed a much lesser increment in shear strength possibly due to the survival factor of the microbes in the peat soils. Thus, a further study should be carried out to investigate this situation in detail.

\section{Acknowledgements}

The authors would like to thank the Ministry of Higher Education and University Technology MARA for the FRGS fund project of a soil treatment of a peat soil by using a full concentration of microbes and the reviewers for their time in reviewing this manuscript. 


\section{References}

[1] M. Abdul Wahed, Effects of organic content on consolidation parameters of peat soil, Faculty of Civil Engineering, 1, (2005) 1-12.

[2] B.K. Bujang, Experimental investigation on Geomechanical properties of tropical organic soils and peat, American J. of Engineering and Applied Science 2, 1, (2009) 184-188.

[3] S. Castanier, G. Le Metayer-Levrel, and J.P. Perthuisot, Carbonates precipitation and limestone genesis - the microbiologist point of view, Geol, 126, (1999) 9-23

[4] R.L. Crawford, M.B. Burbank, T.J. Weaver, B.C. Williams, United States Patent Application Publication, Pub. No.: US2011/0027850 (2011).

[5] J.T. Dejong, M.B. Fritzges, and K. Nusslein, Microbially induced cementation to control sand response to undrained shear, ASCE J. Geotech. Geoenviron, 132 (11), (2006) 1381-1392.

[6] W. de Muynck, D. Debrower, N. De Belie, and W. Verstraete, Microbial carbonate precipitation improves the durability of cementatious materials, Cement and Concrete Res., 38, (2008) 1005-1014.

[7] F. Hammes, , N. Boon, J. de Villiers, and S.D. Siciliano, Strain specific ureolytic calcium carbonate precipitation, Applied and Environmental Microbiology, (2003) 4901-4909.

[8] V. Ramakrishnan, K. Ramesh, and S.S. Bang, Improvement of concrete durability by bacterial mineral precipitation, Proc. ICF 11, (2005) 9736.

[9] D. Sarda, H.S. Choonia, D.D.Sarode, and S.S. LeLe, Biocalcification by Bacillus pasteurii urease: a novel application, Journal Of Industrial Microbiology and Biotechnology, 36(8), (2009) 1111-5. 